\title{
Enhanced Physical Absorption Properties of ZnO Nanorods by Electrostatic Self-Assembly with Reduced Graphene Oxide and Decorated with Silver and Copper Nanoparticles
}

\author{
Lina Z. Yahiya, Mohamed K. Dhahir \\ Institute of laser for postgraduate Studies, University of Baghdad, Baghdad, Iraq \\ E-mail: mohammed@ilps.uobaghdad.edu.iq \\ Corresponding author: lina82zeki@gmail.com
}

\begin{abstract}
The preparation and characterization of innovative nanocomposites based on zinc oxide nanorods (ZNR) encapsulated by graphene $(\mathrm{Gr})$ nanosheets and decorated with silver $(\mathrm{Ag})$, and copper $(\mathrm{Cu})$ nanoparticles $(\mathrm{NP})$ were studied. The prepared nanocomposites (ZNR@Gr/Cu Ag) were examined by different techniques including Field Emission Scanning Electron Microscopy (FESEM), Transmission Electron Microscopy (TEM), Atomic Force Microscopy (AFM), UV-Vis spectrophotometry and fluorescence spectroscopy. The results showed that the ZNR had a good cover of five layers of graphene and decorated with $\mathrm{Ag}$ and $\mathrm{Cu}$ NPs with particles size of about (10-15) nm. In comparison with ZNR, the ZNR@Gr/Cu Ag nanocomposites revealed superior absorption in the entire region of 300-1000 $\mathrm{nm}$. Moreover, the band gap decreased from $3.2 \mathrm{eV}$ of ZNR to $1.2 \mathrm{eV}$ for ZNR@ $\mathrm{Gr} / \mathrm{Cu} \mathrm{Ag}$ nanocomposites. Taking into account the superiority of ZNR@Gr/Cu Ag nanocomposites in terms of easy fabrication, low-cost method, and environmental friendliness, which made it favorable for huge-scale preparation in many applications such as water splitting, sensor, solar cell, antibacterial and optoelectronic devices.
\end{abstract}

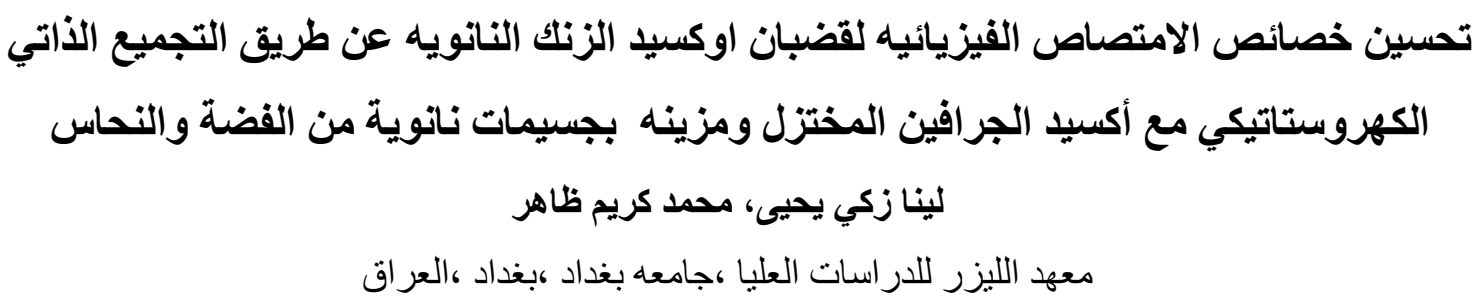

Article info.

Received: Sep. 2020

Accepted: Dec. 2020

Published: Mar. 2021
Key words

Zinc oxide nanorods, graphene oxide, absorption, synthesis, band gap.

(1)




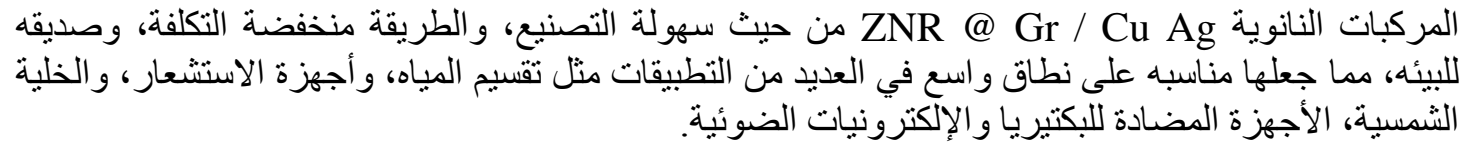

\section{Introduction}

Semiconductor photocatalysis has enticed a noteworthy attention due to its practical applications in many fields including solar energy conversion, environmental remediation, water splitting, antibacterial and optoelectronic devices [1-3]. Amongst different semiconductor materials, zinc oxide $(\mathrm{ZnO})$ has been widely considered as a greatly efficient photocatalyst for the water splitting and dissolution of pollutants owing to its proper energy band, great electron mobility, cost-effective, controllable morphology and friendless environmental [4-7]. Among the other obtainable semiconductor materials, $\mathrm{ZnO}$ is an efficient light absorber in the UV region, because it has a wide band- gap of about $(3.37 \mathrm{eV})[8,9]$. However, the rapid recombination of the photo-induced carriers and the presence of photo-corrosion strictly obstruct the application of $\mathrm{ZnO}$ photocatalysts. In recent years, diversity of techniques has been proposed to improve the physical properties including light absorption, photoactivity and anti-photo corrosion features of $\mathrm{ZnO}$ photocatalysts containing the geometry and facet adjustment, as well combining its heterostructure with an alternative semiconductor or noble metal, and combining with carbon-based graphite nanomaterial (e.g. graphene oxide, fullerenes, monolayer polyaniline, and carbon nanotubes) [10-13]. Graphene (Gr) or reduced graphene oxide (rGO), with its particularly great specialized surface area feature and excellent conductivity, has been often utilized to fabricate $\mathrm{ZnO}-\mathrm{rGO}$ hybrid photocatalysts with improved photoactivity as contrasted to bare $\mathrm{ZnO}[16,17]$. Usually, there are many techniques for preparing ZnO-rGO hybrids [3, 14-16]. Firstly, the one-stage soft integration technique within graphene oxide (GO, the precursor of $\mathrm{Gr}$ ) actions when the phase for nucleation and creating of solvable semiconductor precursors, and then continued by the reduction of GO to Gr Secondly, the hard integration of Gr with good-grainy semiconductor elements. However, each technique has its weaknesses. The hybrids synthesis by the first technique often possesses excellent interfacial interaction on the account of uncontrollable and fewer uniform morphology as contrasted to the last technique. On the other hand, requested morphologies are easily achieved through hard integration on the account of somewhat weak interfacial interaction among $\mathrm{Gr}$ and the semiconductor, so resulting in low photostability and photoactivity $[3,17,18]$. To reinforce the interfacial interaction in Gr-based hybrids, helping electrostatic interactions among $\mathrm{Gr}$ and the semiconductor, including $\mathrm{ZnO}$ through surface alteration has been suggested to ease interfacial bonding in two-steps integration methods [19-21]. In that, some surfactants have been employed to alter the $\mathrm{ZnO}$ surface charge from negative to positive, that reinforces the integrating negative rGO with $\mathrm{ZnO}$ through electrostatic self-assembly method. Furthermore, to further improve the physical properties and electrical conductivity of graphene hybrids for different fields of application, the surface of the hybrid composite decorated with metallic nanoparticles, like $\mathrm{Au}, \mathrm{Ag}, \mathrm{Pt}$ or $\mathrm{Pd}, \mathrm{Cu}$ and $\mathrm{Ni}$, have been proposed owing to the size influence and distinctive microstructures [22-26]. Therein, Huge efforts were focused towards enhancing the ZNR arrays surface by doping with a noble metal [27-29]. Semiconductor and noble metals have been extensively studied for purposes in different competences like photocatalysis, water splitting, optoelectronics, energy conversion, and sensing [30-32]. Consequently, it is essential to prepared $\mathrm{ZnO}-\mathrm{GO}$ hybrids with uniform morphology, small size, and good-contacted interface to 
accomplish excellent physical properties. [33, 34]. In this work, we report the preparation of ZNRs-Gr hybrid decorated with $\mathrm{Ag}$, and copper $\mathrm{Cu}$ NPs with uniform construction, large area uniformity, good interfacial interaction and environmentally friendly via a four-steps preparation method. Synthesis of ZNRs experienced surface charge alteration, preparation of GO using Hummers method, the ZNRs positively charged were afterward gathered with negatively charged GO via electrostatic attraction to preparation ZNR@Gr hybrid. Finally, ZNR@Gr decorated with Ag and $\mathrm{Cu}$ NPs via hydrothermal reduction. The morphological and spectroscopic examinations show that $\mathrm{Ag}$ and $\mathrm{Cu}$ NPs have been distributed regularly on the surface of ZNR@Gr and ZNR and these metals nanoparticles assistance with GO lead to enhance the physical absorption properties of ZNR thin film as reduced the energy gap.

\section{Experimental work \\ Materials}

Zinc nitrate $\left(\mathrm{Zn}\left(\mathrm{NO}_{3}\right)^{2}\right)$ solution (Shanghai, China), hexamethylenetetramine (HMTA) from (New Delhi-110002 INDIA), Graphite powder (sky spring nanomaterials, USA), Sulfuric acid $\left(\mathrm{H}_{2} \mathrm{SO}_{4}\right)$ from (LOBA-Chemie), sodium nitrate $\left(\mathrm{NaNO}_{3}\right)$ from (Sigma-Aldrich), potassium permanganate $\left(\mathrm{KMnO}_{4}\right)$ from (SigmaAldrich), nitric acid $\left(\mathrm{HNO}_{3}\right)$, potassium persulfate $\left(\mathrm{K}_{2} \mathrm{~S}_{2} \mathrm{O}_{8}\right)$, hydrogen peroxide $\left(\mathrm{H}_{2} \mathrm{O}_{2}\right.$, $30 \%$ ), and ethanol $\left(\mathrm{C}_{2} \mathrm{H}_{6} \mathrm{O}\right)$, from (Sigma-Aldrich), Amino-propyl-trimethoxy-silane APTM from (Aladdin, Shanghai, Dishware), $\mathrm{HCuCl}_{4}(25 \mathrm{mM})$ from (Sigma-Aldrich), Silver chloride $\mathrm{AgCl}_{2},(25 \mathrm{mM}$ ) from (Sigma-Aldrich), polyvinyl alcohol (PVA) from (Sigma-Aldrich), and Sodium borohydride $\left(\mathrm{NaBH}_{4}\right)$ from (Sigma-Aldrich). The process for synthesizing the ZNR@ $\mathrm{Gr} / \mathrm{Cu} \mathrm{Ag}$ is displayed in Fig. 1. All the chemical utilized in synthesis have been exploited as received from chemical suppliers without more processing and purification. The GO was prepared by Hummers methods. The ZNRs was prepared by the hydrothermal method. On the other side, the fluorine-doped tin oxide (FTO) was utilized as host substrate for the nanocomposite. This substrate was washed with $50 \mathrm{ml}$ of water, $50 \mathrm{ml}$ of ethanol, in an ultrasonic bath for $20 \mathrm{~min}$ at $90{ }^{\circ} \mathrm{C}$.

\section{Synthesis of ZNRs}

ZNRs were synthesized by the hydrothermal method. Typically, ten drops of Zn $\left(\mathrm{NO}_{3}\right)^{2}$ solution $(0.5 \mathrm{M})$ and ten drops of HMTA $(0.5 \mathrm{M})$ were alternately distilled onto the FTO (Glass sheet electrical connector, UK) substrate. After $10 \mathrm{~min}$, the solution was uniformly distributed on FTO substrate using a spinner, and then FTO was annealed at $200{ }^{\circ} \mathrm{C}$ for $20 \mathrm{~min}$. To be sure that the seeds are formed on the substrate, all the above processes were repeated using hydrothermal method. This solution was poured into a Teflon-sealed stainless-steel autoclave and heated to $122{ }^{\circ} \mathrm{C}$ for $4 \mathrm{~h}$ and then left to cool down. Thereafter, the ZNR were collected by centrifuge, sequentially washed with ethanol and deionized water, followed by drying at $100{ }^{\circ} \mathrm{C}$ for $4 \mathrm{~h}$. 


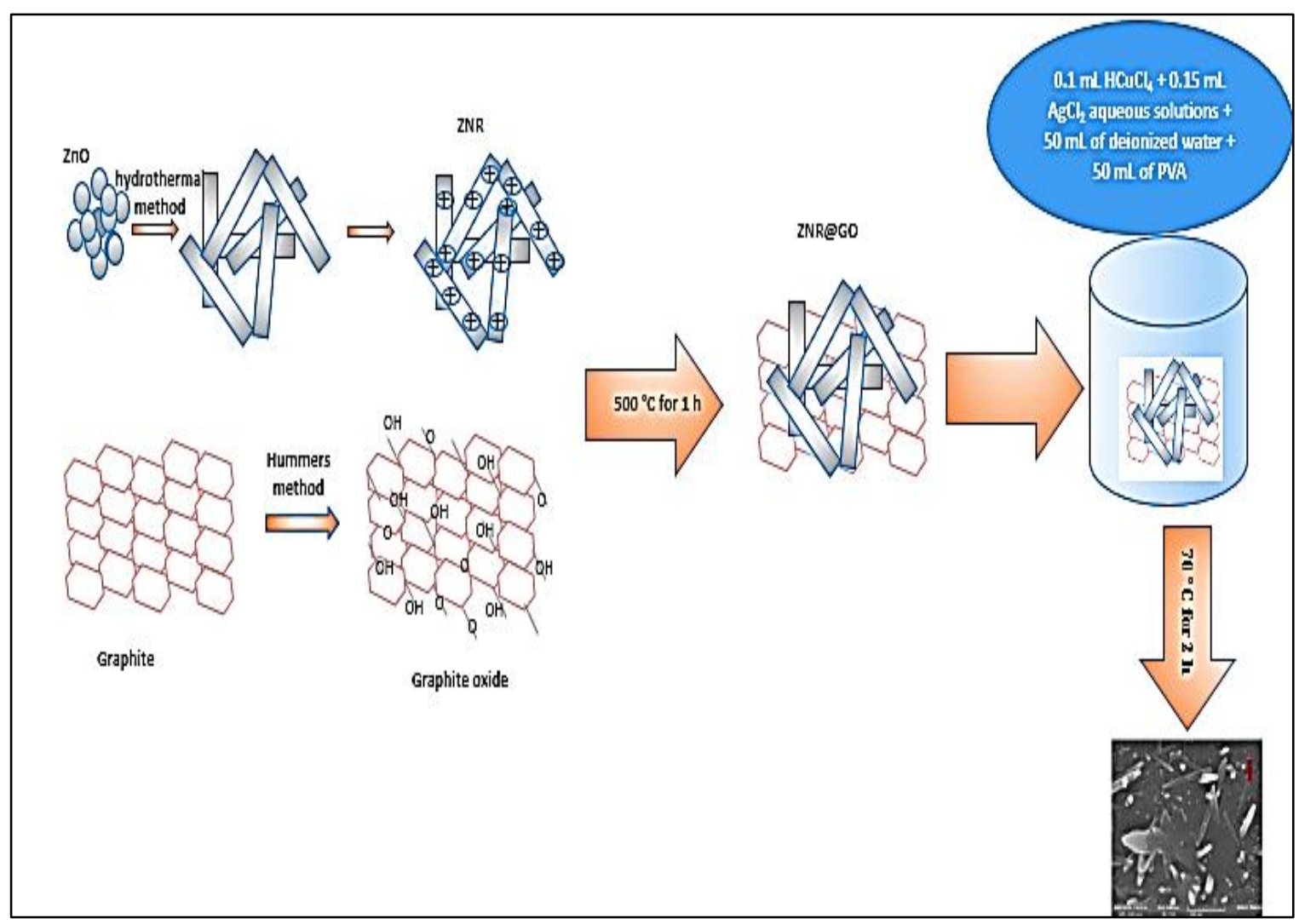

Fig. 1: The steps of synthesis of ZNR@Gr/Cu Ag thin film.

\section{Graphene oxide preparation}

Graphene oxide (GO) was firstly prepared by the oxidation of natural graphite powder according to Hummers method [35]. Typically, $1 \mathrm{~g}$ of graphite powder with average particle size of $7 \mathrm{~nm}$ was added to $23 \mathrm{ml}$ concentrated $\mathrm{H}_{2} \mathrm{SO}_{4}$ with $5 \mathrm{~g}$ of concentrated $\mathrm{NaNO}_{3}$ with stirring in an ice bath for $15 \mathrm{~min}$. Under energetic agitation, the mixture of $3 \mathrm{~g} \mathrm{KMnO}_{4}$ with $500 \mathrm{ml}$ deionized water was added slowly to preserve the temperature of the suspension at $35^{\circ} \mathrm{C}$ and strongly stirred for about $24 \mathrm{~h}$. This was followed by a slow addition of $5 \mathrm{ml}$ diluted $\mathrm{H}_{2} \mathrm{O}_{2}(30 \%)$, the solution was washed by $5 \% \mathrm{M}$ of $\mathrm{HCl}(11.25)+\mathrm{H}_{2} \mathrm{O}(88.75) 37.5 \mathrm{M} \%$. Finally, the resultant solution was heated at $100{ }^{\circ} \mathrm{C}$ for $3 \mathrm{~h}$, for the formation a graphite oxide aqueous dispersion.

\section{Synthesis of graphene covered ZNR@Gr}

ZNR@Gr nanocomposite was prepared through electrostatic self-assembly method by merely mixing the positively charged of the functionalize ZNRs aqueous suspension with the negatively charged of the prepared GO solution, the prepared ZNRs were functionalized with amino-propyl-trimethoxy-silane APTMS by the subsequent step. The ZNR cover can be altered with APTM, in $5 \%$ APTMS/ethanol set obtained a positively charged solation then immersed It with $5 \mathrm{~mL}$ of water mixed with $0.05 \mathrm{ml}$ of GO negatively charge solation. Graphene pollutant is gained using the varied Hummers' methods. Finally, using centrifugation at $9000 \mathrm{rpm}$ for $25 \mathrm{~min}$ to select the appropriate size, then dilute with $100 \mathrm{~mL}$ of water to treat by ultrasonic for $20 \mathrm{~min}$. The modified samples can be submerged in $\mathrm{GO}$ solution with heating at $65^{\circ} \mathrm{C}$ for $4 \mathrm{~h}$, followed by drying at $60{ }^{\circ} \mathrm{C}$ for $2 \mathrm{~h}$ to obtain the ZNR@GO. The samples washed with deionized water. Lastly, it was annealed under temperature of $500{ }^{\circ} \mathrm{C}$ for $1 \mathrm{~h}$ to obtain the ZNR@Gr nanocomposite. 


\section{Synthesis of ZNR/Cu-Ag and ZNR@Gr/Cu Ag thin films}

The $\mathrm{Cu}-\mathrm{Ag}$ alloy nanoparticles were prepared by mildly reducing of $\mathrm{Cu}^{+3}$ from (Nanjing nano technology China) and $\mathrm{Ag}^{+3}$ from (Oocap France SAS) in solution. 0.1 $\mathrm{mL} \mathrm{HCuCl}_{4}(25 \mathrm{mM})$ and $0.15 \mathrm{~mL} \mathrm{AgCl}_{2}(25 \mathrm{mM})$ aqueous solutions can be mixed with $50 \mathrm{~mL}$ of deionized water in a beaker. Next, $50 \mathrm{~mL}$ of PVA, (PVA/ $(\mathrm{Cu}+\mathrm{Ag})$ $(0.5,1)$ weight ratio) and $\mathrm{NaBH}_{4},\left(\mathrm{NaBH}_{4} /(\mathrm{Cu}+\mathrm{Ag}) \mathrm{NP} 5\right.$, molar ratio) mingled solution as mixed into the beaker with continuous stirring. The formed $\mathrm{ZNR} / \mathrm{Cu} \mathrm{Ag}$ and ZNR@Gr arrays can be submerged in the solution for $2 \mathrm{~h}$ and then washed by water. The ZNR/Cu Ag and ZNR@Gr/Cu Ag samples were obtained after drying at $70{ }^{\circ} \mathrm{C}$ for $2 \mathrm{~h}$.

\section{Results and discussion}

\section{Structure characterization of ZNR/Cu Ag and ZNR@Gr/Cu Ag}

To characterize the quantity, roughness, structure and morphology of the sample and confirm the formation the $\mathrm{ZNR} / \mathrm{Cu}-\mathrm{Ag}$ and $\mathrm{ZNR} @ \mathrm{Gr} / \mathrm{Cu} \mathrm{Ag}$ hybrids, energydispersive X-ray (EDX), Scanning Electron Microscopy (SEM), Transmission Electron Microscopy (TEM), and Atomic Force Microscopy (AFM, JPK nano wizard 11 Germany), were carried out. The quantitative analysis of the prepared samples was performed by EDX as shown in Fig. 2 (a-d). From Fig. 2 (a), the EDX spectrum shows strong intensity peaks that denoting $\mathrm{Zn}, \mathrm{O}$ and $\mathrm{Si}$ which were emanated from substrate. This means that the formation of ZNR structure was due to the presence of a suitable surfactant. Fig. 2 (b-d) confirms the realization of graphene oxide coating as well as $\mathrm{Cu}$ Ag decorating the sample. Fig. 2 (c-d) shows the good reacting intensity denoting the $\mathrm{Zn}, \mathrm{Cu}$, and $\mathrm{Ag}$ elements. These results are similar to those obtained by Y. Zhanng et al.[25] Morphological structure was also studied via the SEM (Fig.3) and TEM (Fig.4) techniques. Fig.3(a) confrims that ZNR arrays were in good alignement on the FTO substrate. While, Fig.3(b) and Fig.4 (a-b) show that the ZNR surface was well coated with graphene which is connectig the ZNR arrays. Also, SEM image shows that the graphene coating is comparatively thick, but mostly its thickness is not larger than five layers. Fig.3(c) and Fig.4(b) present the SEM and TEM images of ZNR/Cu $\mathrm{Ag}$ sample, these figures confrim the good-dispersion of $\mathrm{Cu} \mathrm{Ag}$ NPs on ZNR with particle size of (10-15) $\mathrm{nm}$. Also, these figures display that $\mathrm{Cu}$ Ag NPs with random alloy nanoparticle .This agress with the results of R.Su [28]. Fig.3(d) and Fig.4(d-e) display the detailed interstitial structure of ZNR@Gr/Cu Ag sample which confirm that $\mathrm{Cu}$ and Ag NPs were regularly sprinkled on the ZNR@Gr surface and the $\mathrm{CuAg}$ NPs can be graced onto the graphene joined the ZNR arrays. The atomic percentage of the all thin films was listed in Table 1. 

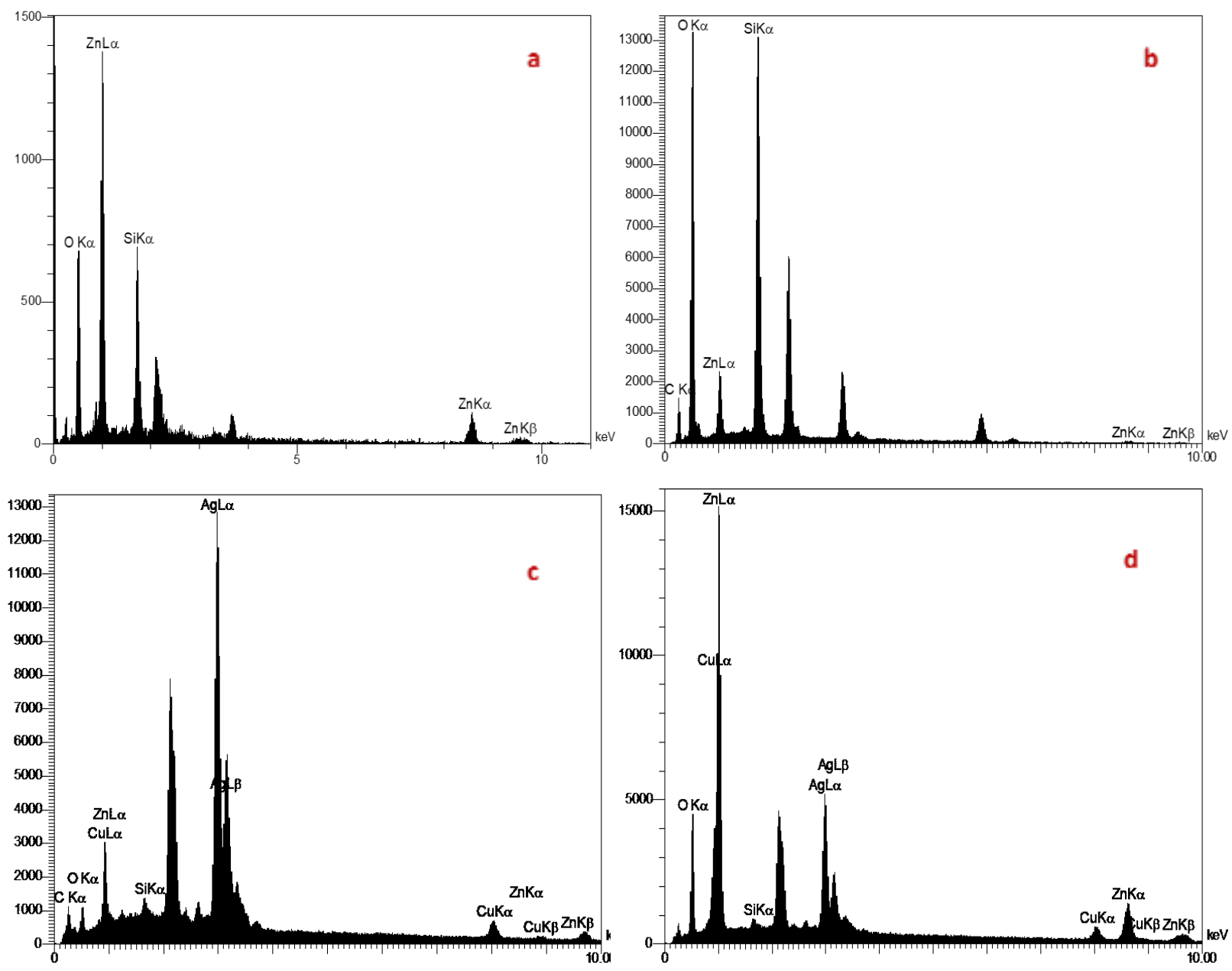

Fig. 2: EDX of thin films (a) ZNR, (b) ZNR@Gr, (c) ZNR/CuAg and (d) ZNR@Gr/CuAg.
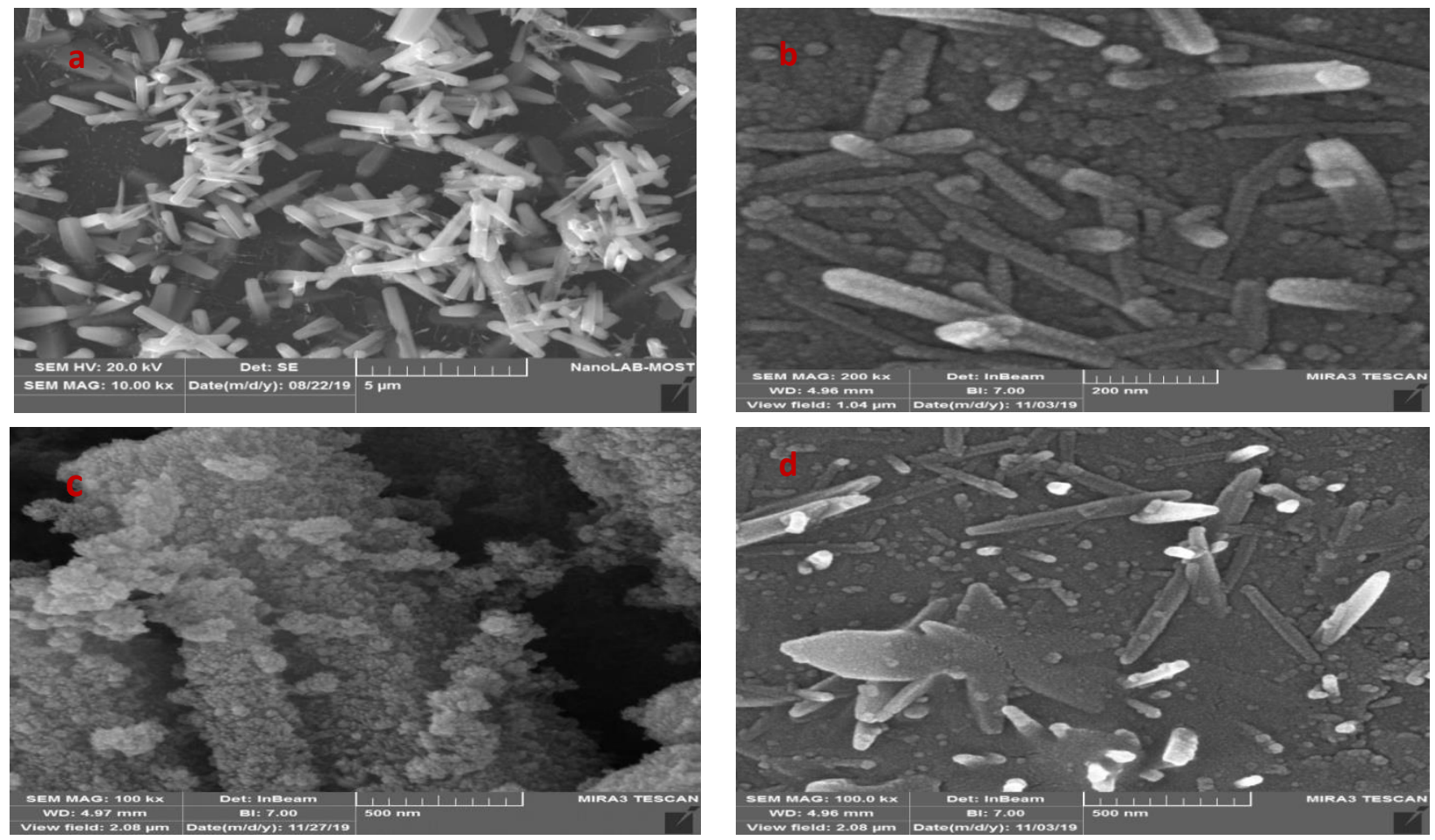

Fig.3: SEM image of thin films (a) ZNR, (b) ZNR@Gr, (c) ZNR/Cu Ag, and (d) SEM image of ZNR@Gr/CuAg. 

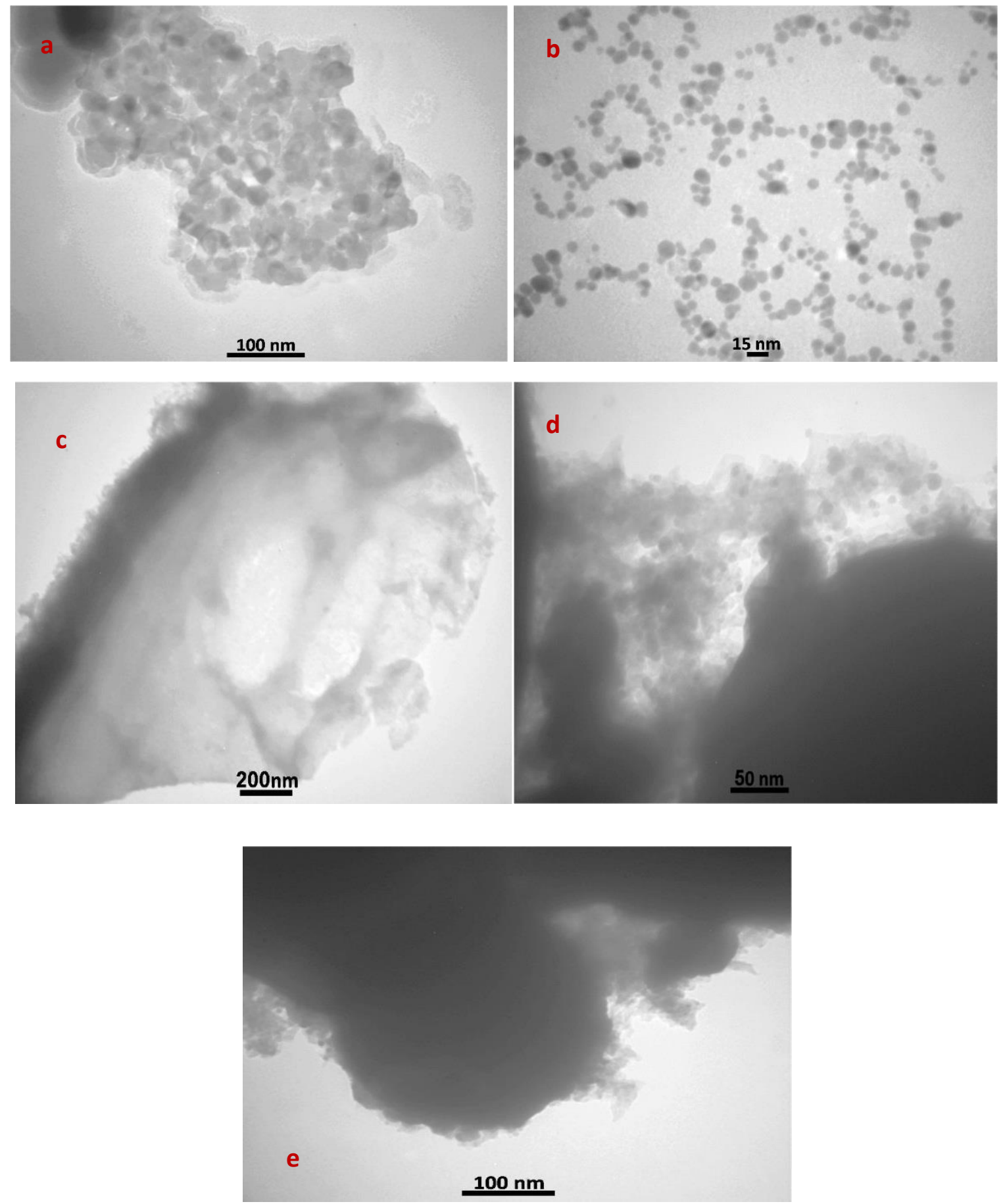

Fig. 4: TEM image of thin films (a-b) ZNR@Gr, (c) ZNR/CuAg, and (d-e)for ZNR@Gr/CuAg. 
Table 1: Weight and atomic percentage of the element's presence in the nanocomposite thin films.

\begin{tabular}{|c|c|c|c|c|}
\hline Thin films & element & Atom percentage & $\begin{array}{c}\text { Wight } \\
\text { percentage }\end{array}$ & $\begin{array}{c}\text { Type electronic } \\
\text { transition }\end{array}$ \\
\hline ZNR & $\mathrm{Zn}$ & 7.58 & 23.22 & L-shell \\
\hline ZNR & $\mathrm{O}$ & 79.22 & 59.40 & K-shell \\
\hline ZNR & $\mathrm{Si}$ & 13.20 & 17.38 & K-shell \\
\hline Total & & $100 \%$ & $100 \%$ & \\
\hline ZNR/Cu Ag & $\mathrm{O}$ & 57.84 & 23.88 & K-shell \\
\hline ZNR/Cu Ag & $\mathrm{Zn}$ & 8.83 & 14.89 & L-shell \\
\hline ZNR/Cu Ag & $\mathrm{Si}$ & 7.07 & 5.12 & K-shell \\
\hline ZNR/Cu Ag & $\mathrm{Cu}$ & 14.85 & 24.36 & L-shell \\
\hline ZNR/Cu Ag & $\mathrm{Ag}$ & 11.41 & 31.75 & L-shell \\
\hline $\mathrm{Total}$ & & $100 \%$ & $100 \%$ & \\
\hline ZNR@ $\mathrm{Gr}$ & $\mathrm{Zn}$ & 2.04 & 7.08 & L-shell \\
\hline ZNR@ Gr & $\mathrm{O}$ & 56.50 & 48.04 & K-shell \\
\hline ZNR@ Gr & $\mathrm{C}$ & 19.90 & 12.71 & K-shell \\
\hline ZNR@ $\mathrm{Gr}$ & $\mathrm{Si}$ & 21.56 & 32.18 & K-shell \\
\hline $\mathrm{Total}$ & & $100 \%$ & $100 \%$ & \\
\hline ZNR@ Gr/Cu Ag & $\mathrm{Zn}$ & 3.25 & 5.97 & L-shell \\
\hline ZNR@Gr/Cu Ag & $\mathrm{O}$ & 42.42 & 19.09 & K-shell \\
\hline ZNR@ Gr/Cu Ag & $\mathrm{Si}$ & 5.57 & 4.40 & K-shell \\
\hline ZNR@Gr/Cu Ag & $\mathrm{C}$ & 20.97 & 7.08 & K-shell \\
\hline ZNR@ Gr/Cu Ag & $\mathrm{Cu}$ & 16.72 & 29.88 & L-shell \\
\hline ZNR@Gr/Cu Ag & $\mathrm{Ag}$ & 11.07 & 33.59 & L-shell \\
\hline
\end{tabular}

Fig. 5 (a-d) show the AFM topography of ZNR, ZNR@Gr, ZNR/Cu-Ag and ZNR@Gr/Cu Ag. It can be observed from these images that all samples show uniformly, well-arranged formation and homogenitly and with better nucleation centers.

The average size distribution of ZNR samples (Fig. 5(a)) is less than $10.05 \mathrm{~nm}$ and with average roughness of $3.5 \mathrm{~nm}$.Fig. 5 (b) displays ZNR@Gr which appears to be uniform with average range size distribution less than $90 \mathrm{~nm}$ and with roughness average of $22.6 \mathrm{~nm}$. From Fig. 5 (c) the average size disruption of $\mathrm{ZNR} / \mathrm{Cu} \mathrm{Ag}$ is less than $30 \mathrm{~nm}$ with roughness of about $7.12 \mathrm{~nm}$. Fig.5 (d) regarding ZNR@ $\mathrm{Gr} / \mathrm{Cu} \mathrm{Ag}$ sample shows its roughness to be of about $24.1 \mathrm{~nm}$ and the average size distribution less than $109.77 \mathrm{~nm}$. Additionally, the average size distribution of graphene oxide was not large than $90 \mathrm{~nm}$, which matches very good with ZNR thin film to prepare the ZNR@Gr structure. The thickness of graphene oxide was about $2.63 \mathrm{~nm}$, which coincides to 5 layers of GO. These results are similar to those of Y.Zhang et al. [25]. From these characterizations, it was well uniform to prepare sprinkled $\mathrm{Cu} \mathrm{Ag} \mathrm{NPs}$ with the average size of (10-15) nm, and these nanoparticles were well-covered ZNR@Gr structure to obtain the ZNR@Gr/Cu Ag and ZNR/Cu Ag composite thin films. The calculated values of surface roughness and the average distribution size are summarized in Table 2 . 

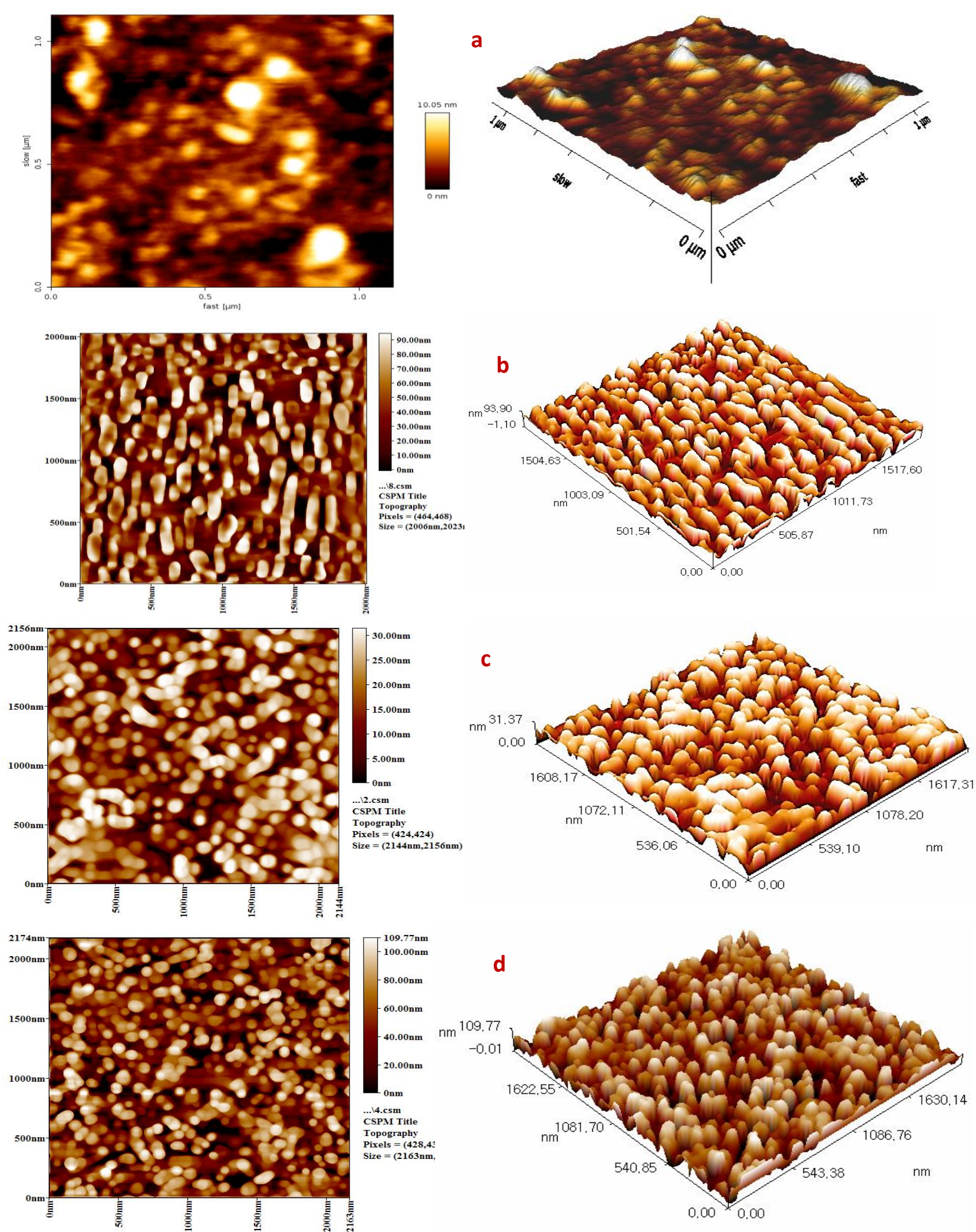

Fig. 5: Atomic force microscope images of the thin films of (a) ZNR (b) ZNR@Gr, (c) ZNR/Cu Ag, and (d)ZNR@Gr/CuAg. 
Table 2: Calculated values of surface roughness and the average particle size of the thin films.

\begin{tabular}{|c|c|c|}
\hline Thin films & $\begin{array}{c}\text { average distribution size of } \\
\text { particles size }(\mathbf{n m})\end{array}$ & $\begin{array}{c}\text { Roughness } \\
\text { (Root mean square) }\end{array}$ \\
\hline ZNR & 10.05 & 3.5 \\
\hline ZNR/Cu Ag & 30 & 7.12 \\
\hline ZNR@ Gr & 90 & 22.6 \\
\hline ZNR@ $\mathrm{Gr} / \mathrm{Cu} \mathrm{Ag}$ & 109.77 & 24.1 \\
\hline
\end{tabular}

\section{Optical properties characterization}

The absorption spectra of ZNR, ZNR/Cu Ag, ZNR@Gr, and ZNR@Gr/Cu Ag samples were characterized using UV-Vis spectrophotometer (SP8001 Taiwan) with wavelength range of $(300-1000) \mathrm{nm}$, as shown in Fig. 6 (a). From this figure, it can be observed that all products exhibit an intensive absorption in the UV region. Also, ZNR/Cu Ag, ZNR@Gr and ZNR@Gr/Cu Ag show a raising in the absorption of light intensity in the range of $(300-1000) \mathrm{nm}$, which confirms an enhancement effect of thin film absorption in this entire range. These results are similar to those obtained by Y. Zhang et el . [25] The optical band gaps of all thin film samples were estimated using Tauc relation, $a h v=A\left(h v-E_{g}\right)^{n}$, where $h v$ is the photon energy $(e V), E_{g}$ is the band-gap energy, and $\mathrm{A}$ is a constant. The factor $\mathrm{n}$ denotes the nature of transition and equal to $1 / 2$ for direct band- gap and 2 for indirect band gap. Fig. 6 (b) displays the plot of $(\mathrm{ahv})^{2}$ versus hv, which reveals that the absorption edge leads to a direct transition between valence and conduction bands. The optical band- gap of the prepared sample was obtained from the linear extrapolation of the Tauc plot. From this plotting, it can be found that the $\mathrm{E}_{\mathrm{g}}$ of $\mathrm{ZNR}$ is $3.2 \mathrm{ev}$. However, the energy gap decreased by doping the $\mathrm{ZNR}$ with $\mathrm{Cu}, \mathrm{Ag}$ and $\mathrm{Gr}$, where the $\mathrm{E}_{\mathrm{g}}$ of $\mathrm{ZNR} / \mathrm{Cu} \mathrm{Ag}$, ZNR@Gr, ZNR@Gr/Cu Ag are 2.8, 2.7 and $1.2 \mathrm{ev}$, respectively. Therefore; the band gap value decreased from $3.2 \mathrm{ev}$ for $\mathrm{ZNR}$ to $1.2 \mathrm{eV}$ for the doped sample ZNR@Gr/Cu Ag. This decrease in the energy band gap value might be attributed to the effect of high reduced of recompilation of photo electron-hole pairs at the range (300-800) $\mathrm{nm}$. In general, the energy gap of ZNR can be reduced when combining with $\mathrm{Cu} \mathrm{Ag}$ or graphene [36]. This means, it exhibits more conductor behavior, also absorption intensity will be double increased for $\mathrm{ZNR} @ \mathrm{Gr} / \mathrm{Cu} \mathrm{Ag}$ thin film as compared ZNR. Generally, the energy band- gap decreases as particle size of the semiconductor NP increases [26]. The photoluminescence spectra (PL) for these samples were studied using spectrophotometer (Hitachi F- 4600 and Shimadzu) in wavelength range of (300-800) nm. PL spectra (Fig. 6 (c)) reflect the recombination efficiency of photo-excited electron-hole pairs and the surface deficiency of semiconductor NP. All these samples have an emission peak around $300 \mathrm{~nm}$. ZNR exhibits a strong emission at the visible region, while the emission intensity was reduced after joining with graphene and $\mathrm{Cu} \mathrm{Ag} \mathrm{NP}$. In addition, $\mathrm{ZNR} @ \mathrm{Gr} / \mathrm{Cu} \mathrm{Ag}$ displays the weakest UV emission. This is reflected to the reduction in the recombination efficiency of photo electron-hole pairs of the semiconductor [37]. 

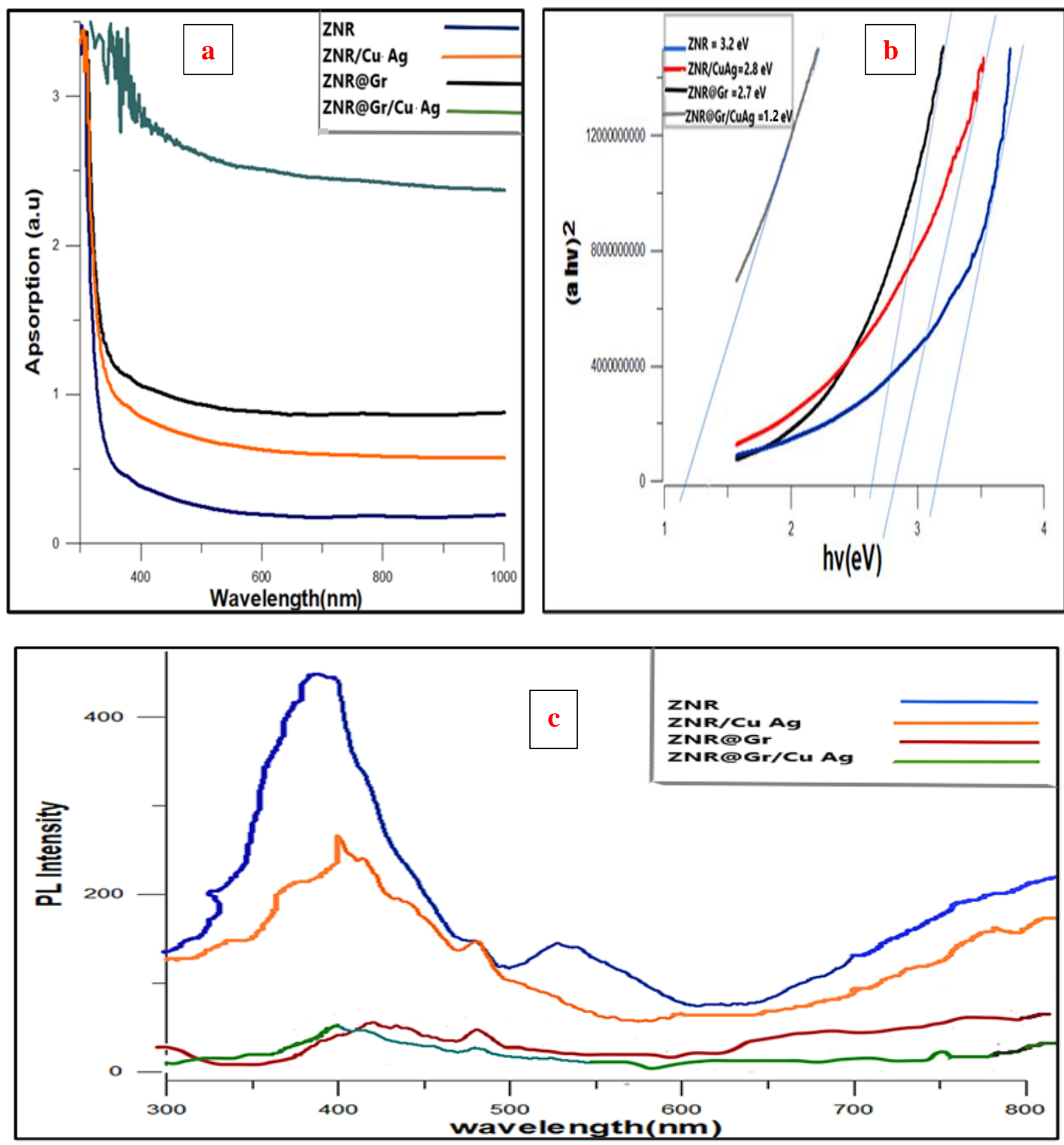

Fig.6: Optical properties characterization of the thin films (a) $U V$-visible spectra, (b) direct optical energy plotted and (c) The photoluminescence $(P L)$ spectra.

\section{Conclusions}

In this work, we report the preparing of promising nanocomposites, namely ZNR $\mathrm{ZNR} / \mathrm{Cu} \mathrm{Ag}, \mathrm{ZNR} @ \mathrm{Gr}$, and ZNR@Gr/Cu Ag. All these nanocomposite thin films were prepared by a Four-step of methods via hydrothermal method, hammer method, electrostatic self-assembly and solution reduction, which was vital in enhancing the physical absorption properties, photoactivity and photostability of ZNR thin film. Absorption analysis showed that ZNR @ Gr / Cu Ag increased the absorbance by twice, which occurred at Vis-IR region, and reduced photoluminescence intensity. Generally, this work offered, suitable and fast method for preparing ZNR nanoparticles attached to $\mathrm{Gr}$ decorated with $\mathrm{Ag}$, and $\mathrm{Cu}$ nanocomposite for effectively enhancing the physical properties, which are useful for many photonic applications. 


\section{Acknowledgments}

This work was supported by Dr. Zainab F. Mahdi, Dr Anas Abdul Hadi Muhammad Jawad at the Institute of Laser for postgraduate studies, University of Baghdad and Dr. Hanna M. Yassin at College of Science University for woman of Baghdad, Baghdad, Iraq.

\section{References}

[1] M. R. Hoffmann, S. T. Martin, W. Choi, and D. W. Bahnemann, Chemical Reviews, 95 (1995) 69-96.

[2] X. Chen, S. Shen, L. Guo, S. S. Mao, Chemical Reviews, 110 (2010) 6503-6570.

[3] F. Wang, Y. Zhou, X. Pan, B. Lu, J. Huang, Z. Ye, Physical Chemistry Chemical Physics, 20 (2018) 6959-6969.

[4] M. K. Dhahir and R. A. Faris, Iraqi Journal of Laser, 15 (2016) 9-12.

[5] J. Xiao, X. Hou, L. Zhao, Y. Li, International Journal of Hydrogen Energy, 41 (2016) 14596-14604.

[6] N. Kislov, J. Lahiri, H. Verma, D. Y. Goswami, E. Stefanakos, M. Batzill, Langmuir, 25 (2009) 3310-3315.

[7] S. Hernández, D. Hidalgo, A. Sacco, A. Chiodoni, A. Lamberti, V. Cauda, E. Tresso, G. Saracco, Physical Chemistry Chemical Physics, 17 (2015) 7775-7786.

[8] R. Chakraborty, S. Dhara, P. K. Giri, International Journal of Nanoscience, 10 (2011) 65-68.

[9] M. A. Hassan, Iraqi Journal of Physics, 10 (2012) 17-23.

[10] S. Safa, R. Sarraf-Mamoory, R. Azimirad, Physica E: Low-dimensional Systems and Nanostructures, 57 (2014) 155-160.

[11] M. Huang, S. Weng, B. Wang, J. Hu, X. Fu, P. Liu, The Journal of Physical Chemistry, C 118 (2014) 25434-25440.

[12] R. Boppella, K. Anjaneyulu, P. Basak, S. V Manorama, The Journal of Physical Chemistry, C 117 (2013) 4597-4605.

[13] H. K. Wahhab, Z. F. Mahdi, R. A. Faris, D. O. Altiafy, Iraqi Journal of Laser, 16 (2017) 25-33.

[14] X. Bai, L. Wang, R. Zong, Y. Lv, Y. Sun, Y. Zhu, Langmuir, 29 (2013) $3097-$ 3105.

[15] N. Zhang, Y. Zhang, Y.-J. Xu, Nanoscale, 4 (2012) 5792-5813.

[16] M.-Q. Yang, N. Zhang, M. Pagliaro, Y.-J. Xu, Chemical Society Reviews, 43 (2014) 8240-8254.

[17] H. Fan, X. Zhao, J. Yang, X. Shan, L. Yang, Y. Zhang, X. Li, M. Gao, Catalysis Communications, 29 (2012) 29-34.

[18] H. Moussa, E. Girot, K. Mozet, H. Alem, G. Medjahdi, R. Schneider, Applied Catalysis B: Environmental, 185 (2016) 11-21.

[19] J. S. Lee, K. H. You, C. B. Park, Advanced Materials, 24 (2012) 1084-1088.

[20] Y. Wang, W. Wang, H. Mao, Y. Lu, J. Lu, J. Huang, Z. Ye, B. Lu, ACS Applied Materials \& Interfaces, 6 (2014) 12698-12706.

[21] B. Weng, M.-Q. Yang, N. Zhang, Y.-J. Xu, Journal of Materials Chemistry, A 2 (2014) 9380-9389.

[22] G. Schmid, Nanoparticles: From Theory to Application (John Wiley \& Sons, 2011).

[23] L. M. Liz-Marzán, Nanometals: Formation and Color Material today Review @ Elsevier Ltd 2004.

[24] I.-Y. Jeon, H.-J. Choi, S.-M. Jung, J.-M. Seo, M.-J. Kim, L. Dai, J.-B. Baek, Journal of the American Chemical Society, 135 (2013) 1386-1393. 
[25] Y. Zhang, Y. Zhang, Y. Guo, L. Wu, Y. Liu, L. Song, RSC Advances, 9 (2019) 2666-2672.

[26] M. Singh, M. Goyal, K. Devlal, Journal of Taibah University for Science, 12 (2018) 470-475.

[27] X. Zhang, Y. Li, J. Zhao, S. Wang, Y. Li, H. Dai, X. Sun, Journal of Power Sources, 269, (2014) 466-472.

[28] R. Su, R. Tiruvalam, A. J. Logsdail, Q. He, C. A. Downing, M. T. Jensen, N. Dimitratos, L. Kesavan, P. P. Wells, R. Bechstein, ACS Nano, 8 (2014) 3490-3497.

[29] C. Zhang, M. Shao, F. Ning, S. Xu, Z. Li, M. Wei, D. G. Evans, X. Duan, Nano Energy, 12 (2015) 231-239.

[30] C. Ng, J. J. Cadusch, S. Dligatch, A. Roberts, T. J. Davis, P. Mulvaney, D. E. Gómez, ACS Nano, 10 (2016) 4704-4711.

[31] I. Venditti, Materials, 10, 97 (2017) 1-18.

[32] E. Della Gaspera and A. Martucci, Sensors, 15 (2015) 16910-16928.

[33] Z. R. Dai, Z. W. Pan, Z. L. Wang, Advanced Functional Materials, 13 (2003) 924.

[34] K. L. Kelly, E. Coronado, L. L. Zhao, G. C. Schatz, J. Phys. Chem., B 107 (2003) 668-677.

[35] R. Zou, T. Xu, X. Lei, Q. Wu, S. Xue, " Solid State Sciences, 99 January (2020) 106067.

[36] Y. Lu, J. Zhang, L. Ge, C. Han, P. Qiu, S. Fang, Journal of Colloid and Interface Science, 483 (2016) 146-153.

[37] M. Khenfouch, M. Baïtoul, M. Maaza, Optical Materials, 34 (2012) 1320-1326. 